\title{
Key Features
}

- Integration. REopt models the complex interactions of multiple thermal and electrical technologies operating concurrently.

- Optimization. The REopt solver engine is based on a mixed integer linear program that provides optimal, least-cost solutions that minimize energy costs subject to specified constraints.

\section{Technologies}

- Photovoltaics (PV)

- Solar hot water

- Solar ventilation-air preheating

- Wind: small, medium, and large

- Biomass: thermal, combined heat and power (CHP), and electric

- Waste-to-Energy: thermal, CHP, and electric

- Landfill Gas: thermal, CHP, and electric

- Diesel and natural gas engine generators

- Ground source heat pumps

- Energy storage

For screening analyses, REopt combines resource data, energy costs, incentives, and economic inputs to identify renewable energy technologies that most cost-efficiently meet defined energy goals. The solution set contains the optimal mix and size of technologies that minimize the life-cycle cost (LCC) of energy over the analysis period.

Outputs for the solution set include capital costs, O\&M costs, and levelized costs of energy. Portfolio optimization capabilities allow multiple sites to be analyzed simultaneously such that agency-wide goals are met most cost-efficiently. Screenings can include sensitivities around costs, incentives, and economic parameters.

\section{Dispatch Strategy Analysis}

REopt can be used to determine the optimal operating strategy for dispatchable energy assets when time series load data (hourly or sub-hourly) and a detailed description of the tariff structure is available. The optimal operating strategy for a 2.5MW PV system combined with a 1-MWh lithiumion battery leverages the on-peak demand and time-of-use rates to maximize the economic returns of the installed energy assets (Figure 1).

- Energy conservation measures
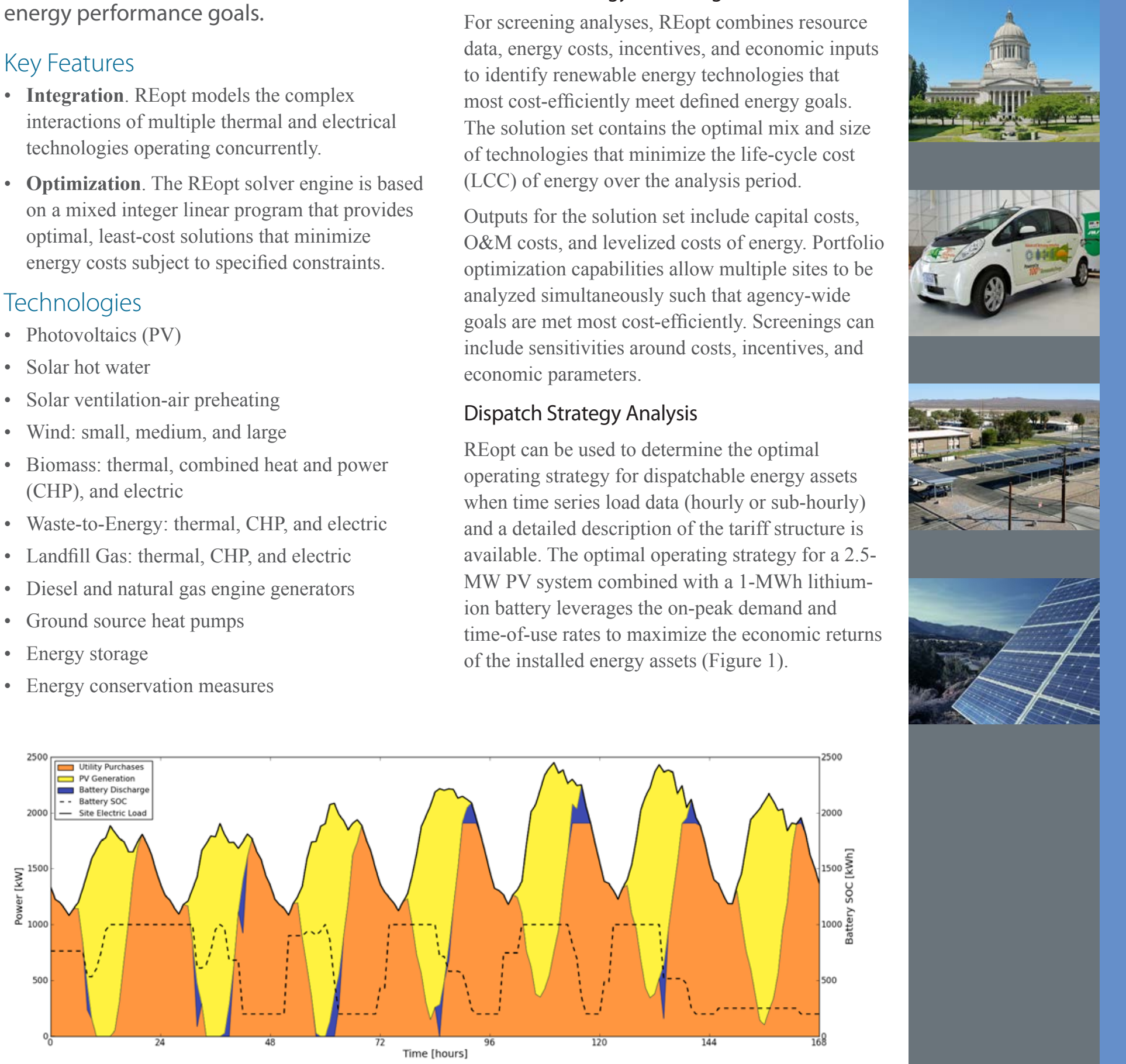

Figure 1. Cost-optimal economic dispatch strategy for a combined PV and battery system 


\section{Model Description}

REopt minimizes the LCC for a site or portfolio of sites subject to various constraints. The Net Present Value (NPV) of the solution is calculated by subtracting the RE case LCC from the current case LCC. The NPV of an optimal solution may be negative if there is a cost to achieve a specified goal.

The constraints governing how REopt builds and dispatches technologies fall into several categories, including: load, resource, operating, sizing and policy constraints. The fundamental load constraint ensures that in each time-step the load is met by some combination of energy purchases, energy generation, energy storage, and load reduction. Optional scenario specific constraints are typically based on agencywide goals such as achieving net zero electricity or obtaining $20 \%$ of electricity from renewable generation.

REopt determines the optimal system size for each technology along with its optimal operating strategy in each timestep. Dispatchable technologies must adhere to minimum turndown constraints but are otherwise permitted to operate at partial loading with the associated loss of efficiency.

\section{Inputs}

For renewable energy screening analyses, REopt uses a combination of client-supplied data and geospatial datasets. For more detailed analyses, these inputs are refined to include time series load information, complex tariff structures, and specific operating characteristics of the energy assets.

\section{Client Data}

Client-supplied data includes the locations of the sites, land available, and utility usage.

\section{Energy Generation and Cost Models}

REopt uses performance models to estimate energy generation for each asset. Capital, O\&M, and feedstock costs are based on past and present market data and NREL research.

\section{Renewable Resource Data}

REopt programmatically queries geospatial databases to compile renewable resource data.

- Solar: Direct normal, global horizontal, and diffuse horizontal irradiance ${ }^{1}$

- Wind: Hourly wind data at 50, 80, and 110 meters on a 20-kilometer grid $^{2}$

- Biomass: Quantity of biomass feedstock available within close proximity ${ }^{3}$

- Municipal Solid Waste: Quantity of refuge available and average tipping fee 4

- Landfill gas: Distance to nearest candidate landfill and potential energy generation. ${ }^{5}$

\section{Incentives and Utility Data}

REopt queries utility rates, policies, and incentives based on site location.

- Incentives including investment tax credits, rebates, and production based incentives are obtained from the Database of State Incentives for Renewables \& Efficiency (DSIRE)

- Export rates for excess energy production are based on local utility wholesale rates ${ }^{6}$

- Interconnection and net metering limits are obtained from DSIRE.

\section{Financial Parameters}

Energy escalation rates are based on Energy Information Administration projections. Appropriate discount rates and depreciation schedules are provided by the client.

\section{Load Profile}

REopt uses simulated time series electrical and thermal load profiles which are based on energy models developed for the appropriate building stock and climate zone.

\footnotetext{
'Data obtained from: Typical meteorological year 3.

2Data obtained from: AWS Truepower.

${ }^{3}$ Data obtained from: Milbrandt, A. A Geographic Perspective on the Current Biomass Resource Availability in the United States. NREL/TP-560-39181. NREL

4Data obtained from: Van Haaren, R.; Themelis, N.; Goldstein, N. "State of Garbage in America." BioCycle Journal (51:10), 2010; pp.16.

${ }^{5}$ Data obtained from: the U.S. Environmental Protection Agency Landfill Methane Outreach Program.

${ }^{6}$ Data obtained from: Ventyx.
}

NREL's deployment and market

transformation activities encompass

the laboratory's full range of tech-

nologies, which span the energy

efficiency and renewable energy

spectrum. NREL staff members educate

partners on how they can advance

sustainable energy applications and

also provide clients with best practices

for reducing barriers to innovation and market transformation.

NREL's mission is to be the leader in technology innovation and to advance renewable energy efforts around the world. Let NREL help propel your organization toward a more sustainable energy future.

For more information about NREL's

deployment and market transformation activities, see our website at www.nrel. gov/tech_deployment.

For more information regarding NREL's REopt tool, contact Kate Anderson at 303-384-7453 or kate.anderson@nrel.gov.

www.nrel.gov/tech_deployment/tools_reopt.html

National Renewable Energy Laboratory 15013 Denver West Parkway

Golden, C0 80401

303-275-3000 - www.nrel.gov NREL is a national laboratory of the U.S. Department of Energy, Office of Energy Efficiency and Renewable Energy, operated by the Alliance for Sustainable Energy, LLC.

\section{NREL/FS-7A40-62320 • June 2014}

Front page photography (from the top): iStock 13737597 Dennis Schroeder, NREL 19893; iStock 12123595;

Dennis Schroeder, NREL 20040; Naval Air Weapon Station, 17642; Warren Gretz, NREL 10611

Printed with a renewable-source ink on paper containing at least $50 \%$ wastepaper, including $10 \%$ post consumer waste. 